\title{
Dog bites and human rabies in the Uthungulu District of KwaZulu-Natal province, 2008-2010: a review of surveillance data
}

\author{
V Kubheka, P Govender, B Margot, LR Kuonza
}

\begin{abstract}
Vusumuzi Kubheka, a,b BSc, MPH, FELTP Resident Premi Govender, ${ }^{\mathrm{c}}$ Hons BA Cur, Assistant Manager Communicable Disease Control Bruce Margot, ${ }^{\mathrm{c}}$ Diploma in Environmental Health, Certificate in Occupational Health, Director of Communicable Disease Control and Environmental Health, KwaZulu-Natal Provincial Department of Health

Lazarus R Kuonza, a,b,d MBChB, MPH, Medical Epidemiologist and Lecturer aSouth African Field Epidemiology and Laboratory Training Programme, Sandringham ${ }^{\mathrm{b} S} \mathrm{School}$ of Health Systems and Public Health, Faculty of Health Sciences, University of Pretoria 'Provincial Department of Health, KwaZulu-Natal province dNational Institute for Communicable Diseases, National Health Laboratory Services, Sandringham E-mail: Ikuonza@gmail.com, lazarusk@nicd.ac.za Keywords: rabies, dog-bite injury, rabies post-exposure management, rabies post-exposure prophylaxis, rabies PEP, rabies vaccination
\end{abstract}

The Uthungulu District in KwaZulu-Natal province is the area that is most affected by rabies in South Africa. Usually, the transmission of rabies to humans occurs through the bites of infected dogs. In 2008 , Uthungulu commenced a programme to eliminate human rabies in the district. This paper describes the epidemiology of dog bites and human rabies in the Uthungulu District from 2008-2010, and the extent of adherence to rabies post-exposure prophylaxis (PEP). The method was a retrospective analysis of dog-bite and human rabies surveillance data that were collected in Uthungulu from January 2008-December 2010. Dog-bite injuries in Uthungulu increased from 1176 in 2008 to 2365 in 2009, and decreased to 1598 in 2010. 0 f 2601 patients who were offered rabies PEP in 2009 and 2010, 83.7\% [95\% confidence interval (CI): 82.4-85.2] completed the treatment. Logistic regression analysis found that investigation of the report by an environmental healthcare practitioner [odds ratio (OR) $=3.95 ; 95 \%$ Cl: $2.43-6.43, p$-value $=0.0001]$, the availability of patient telephone contact details in the healthcare facility's records $(0 \mathrm{R}=1.76 ; 95 \% \mathrm{Cl}: 1.02-3.03, \mathrm{p}$-value $=0.041)$, and bite wounds that were classified as Category 3 exposure injuries $(\mathrm{OR}=2.96 ; 95 \% \mathrm{Cl}: 1.39-6.29, \mathrm{p}$-value $=0.004)$, were independently associated with completion of rabies PEP. Seven human rabies cases were reported (four in 2008, two in 2009 and one in 2010). Annualised human rabies incidence rates decreased from four cases per million in 2008 to one case per million in 2010. The findings suggest that the rabies elimination initiative is having an impact on the reduction of the incidence of human rabies in Uthungulu. The district should strengthen the follow-up of people who are exposed to rabies to ensure PEP completion.

P Peer reviewed. (Submitted: 2012-01-06. Accepted: 2012-07-30.) ๑ SAJEI

South Afr J Epidemiol Infect 2013;28(1):33-40

\section{Introduction}

Rabies is a fatal viral infection that is transmissible between animals and humans through the saliva of an infected animal. ${ }^{1}$ Typically, transmission to humans occurs through the bites of infected animals (mostly dogs) when post-exposure prophylaxis (PEP) is not timely or adequately provided. ${ }^{1}$ The disease remains a global public healthcare problem, killing an estimated 55000 people annually, mostly in the developing countries of Africa and Asia., ${ }^{1,2}$

From 1986-2007, a total of 322 human rabies cases were confirmed in laboratories in South Africa by the National Institute for Communicable Diseases (NICD). Seventy-nine per cent of the cases $(n=255)$ occurred in KwaZulu-Natal $(K Z N)$ province, where the disease has remained endemic over the years. $^{3-5}$ The Uthungulu District in KZN province has reported the highest human fatalities due to rabies and almost all the infections have occurred following bites from infected dogs. The majority of victims were children below the age of 10 years.,

In order to curb the incidence of human rabies in $\mathrm{KZN}$, the provincial Department of Health has implemented a policy that promotes the comprehensive treatment, investigation and documentation of all dog bites that occur in the province. Rabies PEP is available in all healthcare facilities in the province. Healthcare awareness campaigns are regularly conducted to educate the public on rabies and the risk of being bitten by an animal. ${ }^{6}$ Despite these efforts, people continue to die of rabies in KZN province.

In South Africa, incidents of human contact with suspected 
rabid animals, and frank cases of human rabies and human deaths due to rabies, need to be reported to the Department of Health in terms of Section 45 of the Health Act (Act No 63 of 1977)..$^{3,5,7}$ In line with this law, the Uthungulu District Department of Health routinely collects data on all dog bites and human rabies cases. All dog bites in Uthungulu are considered to be potential exposure to rabies because of the district's history of human rabies deaths following transmission of rabies from dogs. Accordingly, all dog bites in the district are treated, investigated and reported to the district's Department of Health. Using the data that are routinely collected by the Department of Health, the current paper describes the epidemiology of dog bites and human rabies in the Uthungulu District from January 2008-December 2010, and the extent of adherence to rabies PEP.

\section{Method}

\section{Study design and setting}

The current study was a retrospective analysis of dog-bite and human rabies surveillance data that were routinely collected by the Uthungulu District Department of Health from January 2008-December 2010. Uthungulu is one of 11 healthcare districts in KZN province, with a population of approximately 900000 people. Uthungulu is further subdivided into six subdistricts, namely Nkandla, Mbonambi, Mthonjaneni, uMhlathuze, Ntambanana and uMlalazi. Uthungulu has 11 hospitals, including three private hospitals and 49 clinics that are scattered throughout the six subdistricts. Figure 1 shows the location of the Uthungulu district in KZN and in South Africa.

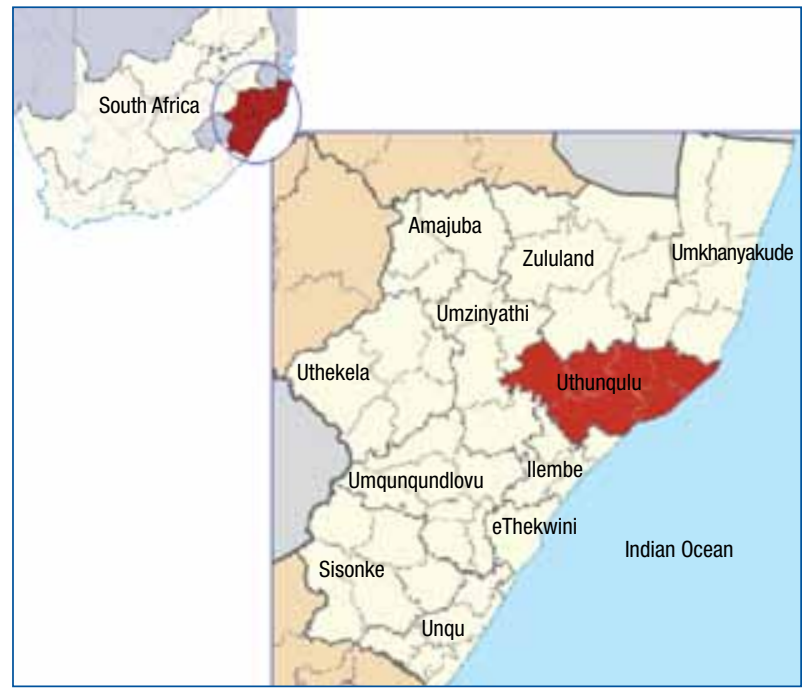

Figure 1: Map showing the geographical location of the Uthungulu District in South Africa and in Kwazulu-Natal province.

\section{Management of dog-bite injuries in Uthungulu}

Rabies post-exposure management is provided free of charge in public healthcare facilities to anyone who has been exposed to the risk of acquiring the rabies virus infection in the Uthungulu District and KZN province. The provincial policy guidelines require that every person who persents with a dog bite, or any other animal bite, is immediately offered the post-exposure management, pending the investigation of the implicated animal. The post-exposure management that is given depends on the clinical assessment and classification of the injury by the attending healthcare professional. According to the provincial guidelines, dog bites are grouped into three categories depending on the degree of the injury and the patient's risk of contracting rabies. Category 1 exposure injury refers to a situation where the animal touches or licks the patient's intact skin (no risk of rabies); Category 2 exposure injury is when the animal scratches the patient's skin without bleeding occurring or when uncovered skin has been nibbled; and Category 3 exposure injury to when the animal bite penetrates the skin, drawing blood, or licks the patient's mucous membrane or an area where there is broken skin..$^{3,5}$

The post-exposure management encompasses local treatment of the bite site, namely flushing and cleaning of the bite wound, and administration of the anti-rabies vaccine. Normally, a total of five rabies vaccination doses should be given over a period of a month on days $0,3,7,14$ and 28 after exposure. (Day 0 is the day of presentation to the healthcare facility). The rabies vaccine doses can be stopped if the dog tests negative for rabies, remains healthy after 10 days following the bite, or if the dog owner produces a valid rabies vaccination certificate. In addition to the vaccination, patients with Category 3 exposure injuries should also receive the anti-rabies immunoglobulin on day 0 . Figure 2 is a flow diagram that summarises the procedures that need to be followed when a person presents to a healthcare facility with a dog bite. ${ }^{3,5}$ The anti-rabies vaccines and the rabies immunoglobulin were available in healthcare facilities in Uthungulu District throughout the period under study.

\section{Dog-bite surveillance system in Uthungulu}

In terms of the Health Act (Act No 63 of 1977), the exposure of humans to rabies and frank human rabies require notification as a medical condition in South Africa. ${ }^{3,5,7}$ Because of the endemicity of rabies in Uthungulu, the district has implemented a policy whereby all incidents of human exposure to rabies infection, such as dog bites, have to be reported to the district's Department of Health within 24 hours of presenting at a healthcare facility. This includes private facilities. When a patient presents to a healthcare facility with a dog bite, the attending clinician completes a notifiable medical condition form. Demographic information, that pertaining to the patient's clinical history, the dog's vaccination history if available, and the treatment administered to the patient is collected. In addition to the requirement for notification, the policy further stipulates that the local healthcare authority (usually the environmental healthcare practitioner) should follow-up and investigate the circumstances surrounding the dog bite. This is in order to ascertain the outcome of the dog, the uptake of the rabies 


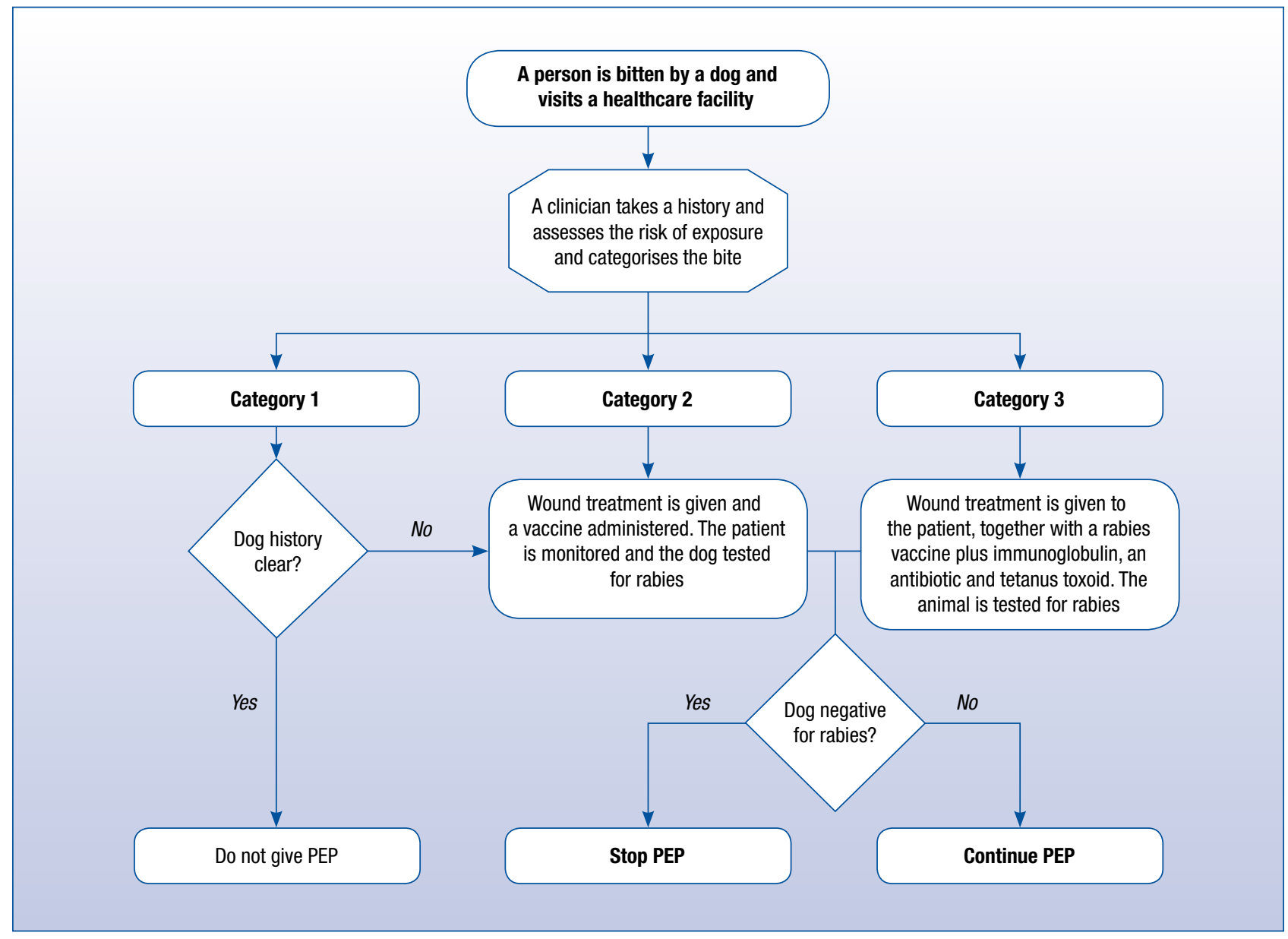

PEP: post-exposure prophylaxis

Figure 2: Algorithm for deciding on the post-exposure management of patients who have been exposed to rabies in the Uthungulu District, $2011^{4}$

PEP and the outcome of the patient. Upon completion of the follow-up, i.e. after administration of the last dose of the rabies vaccine, a case investigation form is completed and submitted to the district's offices where the information is captured electronically on the dog-bite and human rabies surveillance database in the form of a Microsoft Excel ${ }^{\circledR}$ spreadsheet. All suspected human rabies cases and deaths should be comprehensively investigated, reported and captured on the dog-bite and human rabies surveillance database. All human rabies cases that were included in this study were laboratory-confirmed by the special pathogens unit of the NICD in South Africa.

\section{Data management and analysis}

The study population comprised anyone who had been bitten by a dog in the Uthungulu District from January 2008-December 2010 and whose case had been reported to the district's Department of Health. Dog bites that occurred outside this period and those that took place outside the Uthungulu District were excluded from the analysis. In Uthungulu, rabies is usually transmitted to humans through the bite of an infected dog. Accordingly, this analysis focused on dog bites as a potential source of exposure to rabies. Bites by other animals did not form part of the analysis. In Uthungulu, both public and private healthcare practitioners are obliged to report all dog bites that are treated in their respective facilities. Prior to December 2008, healthcare facilities submitted the dogbite surveillance data in the form of monthly aggregated data. From January 2009, the reporting requirements were amended to include the notification of cases of individuals who had been bitten by dogs. Thus, in this study, most of the analysis was conducted on data for 2009 and 2010.

Data were analysed using the Epi Info ${ }^{\circledR}$ statistical software version 3.5.1 (Centers for Disease Control and Prevention, Atlanta, United States). Descriptive analyses were conducted to analyse the distribution of dog bites according to time, place and person. Incidence was calculated using the mid-year population estimates for the respective years as enumerated by Statistics South Africa. Rabies post-exposure completion rates were then calculated. 0 dds ratios (ORs) and 95\% confidence intervals (Cls) were calculated to assess the association between treatment completion and various possible exposure factors. The Fischer's exact test was used to ascertain statistical significance, and a $p$-value of $<0.05$ was considered to be statistically significant. 


\section{Ethical considerations}

Written approval to conduct the analysis was provided by the Uthungulu District Department of Health. Ethical clearance was provided by the KZN provincial research ethics committee and the Faculty of Health Sciences research ethics committee of the University of Pretoria (protocol number: S36/2011). In the study, all analysed data were captured from the district's dog-bite surveillance database. No further information was sought from the patients.

\section{Results}

Cumulatively, 5139 dog bites were reported in the Uthungulu District from 2008-2010 (1 176 in 2008, 2365 in 2009 and 1598 in 2010). Prior to 2009, the dog-bite surveillance data were reported as aggregated data. Therefore, limited analysis could be performed on data for 2008. Variables such as age, sex and subdistrict were not captured. For this reason, most of the findings reported in this paper are based on data for 2009 and 2010.

The age of the patients who reported bites in 2009 and 2010 was captured. The median age of the people bitten by dogs during the two years was 20 years (with a range from 1 - 92 years). The majority (61.3\%) were aged $5-29$ years old. Children aged 5-15 years had the highest incidence of dog bites during 2009 and 2010 (301 and 215 bites per 100000 children respectively) (see Table I). The age structure of the population of Uthungulu was taken into account. Umlalazi and Nkanda subdistricts had the highest incidence of dog bites, while Mthojaneni and Ntambanana subdistricts experienced the lowest. The incidence of dog bites in all the subdistricts of Uthungulu decreased from 2009-2010. This decrease was registered in all the six subdistricts and across all the age categories (Table I).

The majority of the dog bites were classified as Category 2 and Category 3 exposure injuries, $38.8 \%$ and $43.3 \%$ respectively. The dog-bite surveillance system was improved from 2010 to capture information about the anatomical site of the bite and the number of anti-rabies vaccine doses received. A larger proportion of patients were bitten in the lower limbs (72.0\%) compared to other sites. Of the 884 injuries reported for which there was information on vaccination, $38.5 \%$ had been administered all five doses of the rabies vaccine, while $28.3 \%$ had been administered only one dose of the vaccine (Table II).

Of the 3963 dog bite injuries that were reported from 20092010, $2601(65.6 \%)$ of the reports included information on whether or not the patients completed or defaulted on the post-exposure management. Of the 2601 cases, 2178 (83.7\%; 95\% Cl: 82.4-85.2) completed the required treatment according to their level of exposure to rabies. The treatment completion rates were the same for 2009 and 2010 (Table III).

Treatment completion rates were examined when the data were stratified according to various variables (Table IV). Males were more likely to complete PEP compared to females (OR $=1.27 ; 95 \% \mathrm{Cl}: 1.03-1.57, \mathrm{p}$-value $=0.027)$. People with Category 3 exposure injuries were more likely to complete PEP than those with Category 1 exposure injuries $(\mathrm{OR}=1.63 ; 95 \% \mathrm{Cl}: 1.16-2.28, \mathrm{p}$-value $=0.003)$. Patients who had their telephone contact information recorded in the healthcare facility records were more likely to complete PEP than those who had not supplied their contact numbers.

Table I: Distribution of the incidence of dog bites reported in the Uthungulu District of KwaZulu-Natal province, January 2009-December 2010

\begin{tabular}{|c|c|c|c|c|}
\hline \multirow[t]{2}{*}{ Characteristic } & \multicolumn{2}{|c|}{2009} & \multicolumn{2}{|c|}{2010} \\
\hline & Number of cases & $\begin{array}{c}\text { Incidence per } \\
100000 \text { population* }\end{array}$ & Number of cases & $\begin{array}{c}\text { Incidence per } \\
100000 \text { population* }\end{array}$ \\
\hline \multicolumn{5}{|l|}{ Sex } \\
\hline Male & 1220 & 259 & 821 & 173 \\
\hline Female & 1110 & 227 & 762 & 154 \\
\hline \multicolumn{5}{|l|}{ Age-group categories } \\
\hline $0-4$ years & 167 & 147 & 87 & 79 \\
\hline $5-15$ years & 777 & 301 & 511 & 215 \\
\hline $16-29$ years & 577 & 197 & 395 & 137 \\
\hline $30-59$ years & 553 & 222 & 399 & 157 \\
\hline 60 years and above & 130 & 233 & 91 & 159 \\
\hline \multicolumn{5}{|c|}{ Subdistrict where the dog bite was reported } \\
\hline Umhlathuze & 831 & 261 & 630 & 196 \\
\hline Umlalazi & 865 & 364 & 499 & 208 \\
\hline Nkandla & 400 & 283 & 299 & 210 \\
\hline Umbonambi & 102 & 187 & 56 & 102 \\
\hline Mthonjaneni & 93 & 81 & 56 & 48 \\
\hline Ntambanana & 19 & 21 & 13 & 14 \\
\hline
\end{tabular}

*: Incidence rates were calculated using mid-year population estimates obtained from Statistics South Africa 
Table II: Description of reported dog bites in the Uthungulu District of KwaZulu-Natal province, January 2009-December 2010

\begin{tabular}{|l|c|c|}
\hline \multirow{2}{*}{ Characteristic } & \multicolumn{2}{|c|}{ Frequency } \\
\cline { 2 - 3 } & (n) & $\%$ \\
\hline Category of exposure ( $\mathbf{n}=\mathbf{3}$ 963) & 441 & 11.1 \\
\hline Category 1 & 1538 & 38.8 \\
\hline Category 2 & 1717 & 43.3 \\
\hline Category 3 & 267 & 6.7 \\
\hline Missing & & \\
\hline Anatomical site of the dog bite (n= 582) & 419 & 72.0 \\
\hline Lower limbs (feet, legs and buttocks) & 97 & 16.6 \\
\hline Upper limbs (hands, arms and shoulders) & 18 & 3.1 \\
\hline Main body trunk & 18 & 3.1 \\
\hline Head, face and neck & 30 & 5.1 \\
\hline Multiple sites (more than one injury) & & \\
\hline Number of anti-rabies vaccine doses received (n= 884)* & 250 & 28.2 \\
\hline One & 143 & 16.2 \\
\hline Two & 98 & 11.1 \\
\hline Three & 53 & 6.0 \\
\hline Four & 340 & 38.5 \\
\hline Five & & \\
\hline
\end{tabular}

*: The information on the anatomical site of the bite and the number of vaccine doses was only added to the database in 2010 . These figures represent only part of 2010 .
Table III: Rabies post-exposure prophylaxis completion rates among patients who presented with dog bites in the Uthungulu District, January 2009-December 2010

\begin{tabular}{|l|c|c|c|c|c|c|}
\hline \multirow{2}{*}{$\begin{array}{l}\text { PEP } \\
\text { completion }\end{array}$} & \multicolumn{3}{|c|}{2009} & \multicolumn{3}{c|}{2010} \\
\cline { 2 - 7 } & $\begin{array}{c}\mathbf{n = 1} \\
\mathbf{5 5 8}\end{array}$ & $\%$ & $\mathbf{9 5 \%} \mathbf{C I}$ & $\begin{array}{c}\mathbf{n = 1} \\
\mathbf{0 4 1}\end{array}$ & $\%$ & $\mathbf{9 5 \%}$ CI \\
\hline $\begin{array}{l}\text { Completed } \\
\text { PEP }\end{array}$ & 1306 & 83.8 & $\begin{array}{c}81.9- \\
85.6\end{array}$ & 872 & 83.8 & $\begin{array}{c}81.4- \\
85.9\end{array}$ \\
\hline $\begin{array}{l}\text { Defaulted } \\
\text { PEP }\end{array}$ & 252 & 16.2 & $\begin{array}{c}14.8- \\
18.5\end{array}$ & 169 & 16.2 & $14.1-$ \\
\hline
\end{tabular}

Cl: confidence interval, PEP: post-exposure prophylaxis

PEP completion was recorded for 2601 of the 3963 dog bite injuries that were reported in 2009 and 2010, hence the calculated rates were based on the 2601 records.

However, the association was not statistically significant $(\mathrm{OR}=1.16$; $95 \% \mathrm{Cl}$ : 0.93-1.43, p-value $=0.186$ ) (Table IV). Findings from the logistic regression analysis showed that Category 3 exposure injuries, investigation and follow-up of patients by environmental healthcare practitioners and the availability of patients' telephone contact details were all independently associated with completion of the rabies vaccine PEP (Table V).

Table IV: Bivariate analysis association between various demographic and exposure factors and compliance to rabies vaccine post-exposure prophylaxis among people bitten by dogs in the Uthungulu District, 2009-2010

\begin{tabular}{|c|c|c|c|c|c|c|c|}
\hline \multirow[t]{2}{*}{ Characteristic } & \multicolumn{2}{|c|}{ Completed PEP } & \multicolumn{2}{|c|}{ Defaulted PEP } & \multirow{2}{*}{ Odds ratio } & \multirow{2}{*}{$\begin{array}{c}95 \% \\
\text { confidence } \\
\text { interval }\end{array}$} & \multirow{2}{*}{ p-value } \\
\hline & $\mathbf{n}$ & $\%$ & $\mathbf{n}$ & $\%$ & & & \\
\hline \multicolumn{8}{|l|}{ Age-group categories ( $n=2455)$} \\
\hline $0-4$ years & 136 & 6.6 & 19 & 4.7 & 1 & Ref & \\
\hline $5-15$ years & 498 & 24.3 & 131 & 32.2 & 0.53 & $(0.31-0.91)$ & $0.015^{\star}$ \\
\hline $16-29$ years & 555 & 27.1 & 84 & 20.6 & 0.92 & $(0.52-1.62)$ & 0.768 \\
\hline $30-59$ years & 727 & 35.5 & 149 & 36.6 & 0.68 & $(0.38-1.16)$ & 0.140 \\
\hline 60 years and above & 132 & 6.4 & 24 & 5.9 & 0.77 & $(0.38-1.54)$ & 0.425 \\
\hline \multicolumn{8}{|l|}{ Sex of patient $(n=2572)$} \\
\hline Female & 1054 & 49 & 181 & 43.1 & 1 & Ref & \\
\hline Male & 1098 & 51 & 239 & 56.9 & 1.27 & $(1.03-1.57)$ & $0.027^{*}$ \\
\hline \multicolumn{8}{|l|}{ Patient has telephone contact ( $n=2601$ ) } \\
\hline No & 781 & 35.9 & 166 & 39.2 & 1 & Ref & \\
\hline Yes & 1397 & 64.1 & 257 & 60.8 & 1.16 & $(0.93-1.43)$ & 0.186 \\
\hline \multicolumn{8}{|l|}{ Category of exposure ( $n=2496)$} \\
\hline Category 1 & 230 & 11 & 63 & 15.3 & 1 & Ref & \\
\hline Category 2 & 883 & 42.4 & 186 & 45.1 & 1.30 & $(0.93-1.81)$ & 0.018 \\
\hline Category 3 & 971 & 46.6 & 163 & 39.6 & 1.63 & $(1.16-2.28)$ & $0.003^{\star}$ \\
\hline \multicolumn{8}{|l|}{ Anatomical site of dog bite $(n=479)$} \\
\hline Lower limbs (feet, legs and buttocks) & 268 & 72.6 & 79 & 71.8 & 1 & Ref & \\
\hline Upper limbs (hands, arms and shoulders) & 66 & 17.9 & 16 & 14.5 & 1.22 & $(0.64-2.32)$ & 0.523 \\
\hline Main body trunk & 10 & 2.7 & 4 & 3.6 & 0.74 & $(0.21-2.87)$ & 0.613 \\
\hline Head, face and neck & 7 & 1.9 & 6 & 5.5 & 0.34 & $(0.10-1.19)$ & 0.059 \\
\hline Multiple sites (more than one injury) & 18 & 4.9 & 5 & 4.5 & 1.06 & $(0.36-3.38)$ & 0.909 \\
\hline
\end{tabular}

*: Shows variables that were statistically significant at the $5 \%$ level of significance ( $p$-value $<0.05)$. Note: records with missing information were excluded PEP: post-exposure prophylaxis 
Table V: Logistic regression analysis of factors associated with completion of rabies vaccine post-exposure prophylaxis among people bitten by dogs in the Uthungulu District, 2009-2010

\begin{tabular}{|c|c|c|c|}
\hline Variable & OR & $95 \%$ CI & p-value \\
\hline $\begin{array}{l}\text { Category } 3 \text { exposure injury (referent = } \\
\text { Category } 1 \text { exposure) }\end{array}$ & 2.96 & $\begin{array}{l}1.39- \\
6.29\end{array}$ & 0.004 \\
\hline $\begin{array}{l}\text { Dog bite injury was followed-up and } \\
\text { investigated by an EHP }\end{array}$ & 3.95 & $\begin{array}{l}2.43- \\
6.43\end{array}$ & 0.000 \\
\hline $\begin{array}{l}\text { Patient telephone contact details available } \\
\text { in medical records }\end{array}$ & 1.76 & $\begin{array}{l}1.02- \\
3.03\end{array}$ & 0.041 \\
\hline
\end{tabular}

Cl: confidence interval, EHP: environmental healthcare practitioner

Seven human rabies cases were diagnosed during the threeyear period, giving an average annualised rabies attack rate of 136 rabies cases per 100000 dog-bite injuries (7/5 139). Of these, four died in 2008, two in 2009 and one in 2010. Six of the seven patients reported late to the healthcare facility after the dog-bite. One reported on time, but was not offered rabies PEP at the healthcare facility. Of the six that reported late to the facility, two had visited traditional healers before going to the healthcare facility. The yearly rabies attack rate among dog-bite injury cases and the yearly rabies incidence among the total population in the Uthungulu District have both decreased steadily from 2008 to 2010 (Table VI).

\section{Discussion}

Table Vl: Rabies attack rate among patients who sustained dog-bite injuries in the Uthungulu District, January 2009-December 2010

\begin{tabular}{|c|c|c|c|}
\hline Year & $\begin{array}{c}\text { Human rabies } \\
\text { deaths }\end{array}$ & $\begin{array}{c}\text { Rabies attack } \\
\text { rate/100 000 dog- } \\
\text { bite injuries/year }\end{array}$ & $\begin{array}{c}\text { Rabies incidence } \\
\text { rate/100 000 } \\
\text { population/year }\end{array}$ \\
\hline 2008 & 4 & 340 & 0.4 \\
\hline 2009 & 2 & 84 & 0.2 \\
\hline 2010 & 1 & 63 & 0.1 \\
\hline
\end{tabular}

Rabies incidence rates were calculated using mid-year population estimates for the Uthungulu District as enumerated by the Statistics South Africa.

Dog-bite injuries and human rabies remain significant public healthcare problems in the Uthungulu District. The incidence of dog-bite injuries in Uthungulu increased from 2008 to 2009 , and then decreased markedly in 2010. Since 2008, the KZN province, in alliance with various local and external partners, has increased efforts to control and eliminate rabies in Uthungulu. ${ }^{5,9,10}$ The implemented control efforts include increasing rabies awareness at community level, improving access to rabies post-exposure management for people who have been bitten by dogs or other animals, and mass vaccination of dogs. ${ }^{10,11}$ Increased community awareness possibly led to more people seeking treatment for dog-bite injuries in 2009, hence the perceived increased incidence of dog-bite injuries during 2009. In addition, increased understanding of the requirements to report dog-bite injuries among the healthcare professionals could also have contributed to the increased number of reported injuries, since the clinicians who attended to people with dog-bite injuries were then more knowledgeable about the management of the injuries and the need to report them. The decline in the incidence of dog-bite injuries in 2010 could partly be attributed to additional rabies control measures that were introduced in the district in 2008. Besides vaccinating as many dogs as possible against rabies, the district adopted a number of new strategies that targeted reducing the dog population in the district. These measures included sterilisation of male dogs, mass administration of contraceptives to female dogs and euthanising stray and unmanageable dogs. ${ }^{10}$ The use of sterilisation and contraceptives was directed at reducing the number of new dogs born into the district. The impact of these measures was only realised in 2010.

The incidence of rabies in the Uthungulu District steadily decreased from 2008-2010. This trend suggests that the rabies control efforts that were implemented in the district since 2008, under the rabies elimination initiative, were successful. Since 2008, the World Health Organization, the Alliance for Rabies Control, and Partners for Rabies Prevention and the Bill and Melinda Gates Foundation have joined the Department of Health and the Department of Agriculture in an effort to control and eliminate rabies in KZN province. ${ }^{5,10,11}$ These efforts have increased awareness of rabies in the province, have increased the rabies vaccination coverage in dogs and have also improved the accessibility of rabies PEP for people who have been bitten by dogs in the province, hence the reduction in the incidence of rabies in the Uthungulu District. As a result of this collaborative effort, on 24 July 2011, KZN province celebrated its first year, in more than two decades, without a report of a human rabies case. ${ }^{12}$ Although it is possible that some dog-bite injury cases, and possibly rabies cases, went undetected in the district during the period, the Uthungulu District has maintained a relatively high-standard, dog-bite surveillance system. ${ }^{9}$ Additionally, in South Africa, human rabies cases have followed the trend of the animal rabies cases (dogs). Animal rabies cases in KZN province have decreased gradually from 363 in 2007 to an estimated 156 cases in $2010 .^{10}$ Therefore, these figures support the statistics that show a decrease in human rabies cases.

The majority of the dog-bite injuries were classified as Category 2 and Category 3 exposures. A dog-bite injury is classified as a Category 1 exposure when the dog touches or licks an intact skin, without breaking the skin. Since no physical wound results, most people would not consider this to be an injury, and would not visit a healthcare facility to receive rabies post-exposure management. Therefore, it is plausible that there was underreporting of exposures that fell into this category. This would have resulted in an inaccurate assumption that these injuries did not occur.

In 2009 and 2010, the highest incidence of dog-bite injuries was in children aged 5-15 years. These findings are not surprising. Globally, many studies have shown that generally, children are at greater risk of being bitten by a dog than any other age group. ${ }^{13-17}$ Dogs tend to act in a dominant manner towards children because of their small size. This puts them at greater risk of injury than adults. Additionally, children are usually inquisitive and interested in dogs, but they lack the 
ability to fend off attacks by animals. This constitutes an added risk of injury for children. Because of this high risk of dog-bite injury, most rabies victims tend to be children below the age of 10 years. $^{3,16}$

The high rate of default (16.3\%) among people who were bitten by dogs in the Uthungulu District with regard to rabies PEP was of concern. Patients with Category 3 exposure injuries were more likely to complete the rabies PEP than those with Category 1 exposure injuries. A bite is classified as a Category 3 exposure injury when the person has sustained at least one transdermal injury or contamination of the mucous membrane with saliva. A Category 3 exposure injury is usually a deep wound, and naturally people would consider this to be a serious injury. Accordingly, they would adhere to the treatment recommended by healthcare personnel. In contrast, people with Category 1 and 2 exposure injuries tend to have relatively minor wounds which quickly heal. They might not recognise the importance of continuing to visit the healthcare facility for more rabies PEP doses.

Patients who provided telephone contact information when they presented to the healthcare facility were more likely to complete rabies PEP. In the Uthungulu District, generally, municipal clinics and private clinics phone patients, or send short text messages, to remind them of the dates for the next vaccine dose or to follow them up when they miss a dose. Unfortunately, the majority of the government healthcare facilities don't make use of the telephone to remind patients to present for the rabies PEP vaccine doses. Encouraging government healthcare facilities to do so could assist in improving adherence to rabies PEP, and thus reduce the risk of people who die from rabies.

Of the seven human rabies cases that occurred during the three years, six of them reported late for rabies PEP. Any death of a person from rabies should be viewed as a healthcare system failure. ${ }^{3}$ Human rabies can be completely prevented through a combination of the vaccination of host reservoirs (dogs) and the provision of appropriate rabies post-exposure management to those exposed to these reservoirs. However, for the rabies control programme to be successful, community awareness of preventive measures is crucial. Reports indicate that two of the seven patients who died of rabies sought treatment from local traditional healers for their dog-bite injuries before visiting the healthcare facilities. This is a cause for concern. This suggests lack of community awareness on the risk of acquiring rabies from dog-bite injuries and a lack of knowledge of the availability of rabies PEP. For the rabies elimination drive to be a success, it might be worthwhile for the district's authorities to liaise with traditional healers. The latter could be educated on the importance of referring people who are bitten by animals to healthcare facilities for rabies PEP. It is particularly worrying that one of the seven people who died of rabies visited the healthcare facility for treatment of the dog bite, but was not offered a rabies PEP vaccination. The attending healthcare professional overlooked the administration of the rabies PEP.
Rabies is a priority disease in Uthungulu and all healthcare professionals in the public and private facilities in the district should maintain a high index of suspicion when treating people with animal-bite wounds.

There are multiple limitations that should be considered when interpreting the findings of this analysis. Firstly, some data fields on the dog-bite surveillance dataset were incomplete. There is a possibility that the accuracy of some of the findings reported in this paper might have been compromised. Secondly, it is also possible that some dog-bite injuries that occurred during the study period were not reported to healthcare facilities. Our findings may have underestimated the true incidence of dog-bite injuries, and possibly that of human rabies, in the Uthungulu District during the study period. Thirdly, during the study period, the Uthungulu District Department of Health continuously improved the quality and amount of data that was captured on the dog-bite surveillance system database. The resultant changes made our analysis complex and difficult, since new variables were added to the database each year. Despite these limitations, this paper illustrates that routine dog-bite surveillance provides an accessible and valuable source of epidemiological data and emphasises the importance of routinely analysing data that are collected through the surveillance systems.

\section{Conclusion}

Dog-bite injuries and human rabies continue to be significant public healthcare problems in the Uthungulu District. The collaborative efforts that are being implemented in KZN province are making a positive impact in reducing the incidence of the injuries, as well as reducing the number of people dying from rabies. As the rabies elimination drive continues in KZN province, continuing surveillance of animal bites and rabies is needed in order to guide and evaluate the progress of the rabies elimination efforts. In addition, continuing awareness campaigns among community members and healthcare professionals is also crucial to ensure that the surveillance system achieves its intended objectives.

\section{Acknowledgements}

The authors would like to thank all the staff from the South African Field Epidemiology and Laboratory Training Programme, the KZN Provincial Department of Health, the Uthungulu District Department of Health and the School of Health Systems and Public Health at University of Pretoria, who provided valuable technical contributions to this study. The authors also acknowledge the Special Pathogens Unit, National Institute for Communicable Diseases National Health Laboratory Service for laboratory confirmation of all human rabies cases.

The authors acknowledge the KwaZulu-Natal Provincial Department of Health and the Uthungulu District Department of Health for granting permission to conduct the study and providing all the requested valuable information. 


\section{Conflict of interest}

The authors have no commercial or other association that might pose a conflict of interest.

\section{Declaration}

This project received some funding from the South African Field Epidemiology and Laboratory Training Programme and the KwaZulu-Natal Provincial Department of Health.

\section{References}

1. Hemachuda T, Meslin F, Rupprecht C, Wilde H. Rabies. In: Heymann DL, editor. Control of communicable diseases manual. $19^{\text {th }}$ ed. Washington, DC: American Public Health Association, 2008; p. 498-505.

2. World Rabies Day: 28 September 2011. World Health Organization [homepage on the Internet]. c2011. Available from: http://www.who.int/mediacentre/events/annual/ world_rabies_day/en/

3. Bishop GC, Durrheim DN, Kloeck PE, et al. Rabies: a guide for the medical, veterinary and allied professions. 2nd ed. Pretoria: Government Printers, 2010; p. 32-52. National Institute for Communicable Diseases [homepage on the Internet]. c2011. Available from: http:// www.nicd.ac.za/assets/files/B5_rabies_revised_2010.pdf

4. Guidelines for the medical management of rabies in South Africa. Department of Health 1997 [homepage on the Internet]. Available from: http://www.nbi-kzn.org.za/download/ rabies_guide.pdf

5. Global alliance for rabies control. Rabid Bytes Newsletter [homepage on the Internet] 2011. Available from: http://www.rabiescontrol.net/assets/files/resources/newsletters/ GARCnewsletter24.pdf

6. ICAM Coalition report on rabies control project in KwaZulu-Natal in South Africa: February 2009. World Health Organization [homepage on the Internet]. 2011. Available from: http:// www.who.int/rabies/ICAM_report_KZN_rabies_project_Feb_09.pdf
7. Health Act No. 63 of 1977. Government of South Africa [homepage on the Internet]. 2011. Available from: http://www.kznhealth.gov.za/healthact1977.pdf

8. Wikipedia. uThungulu District Municipality [homepage on the Internet]. c2012. Available from: http://en.wikipedia.org/wiki/UThungulu_District_Municipality

9. Celebrating one year without a reported human case of rabies in KZN. World Health Organization [homepage on the Internet]. 2011. Available from: http://www.who.int/rabies/ Celebrating_one_year_rabies_free_KwaZuluNatal/en/

10. NelL,LeRouxK,AtlasR.Meetingtherabiescontrolchallenge inSouthAfrica.Microbemagazine [homepage on the Internet]. 2009. c2011. Available from: http://www.microbemagazine. org/index.php/02-2009-home/57-meeting-the-rabies-control-challenge-in-south-africa

11. Rabies: Bill and Melinda Gates Foundation Fund WHO-coordinated project to control and eventually eliminate rabies in low-income countries. World Health Organization [homepage on the Internet]. c2011. Available from: http://www.who.int/rabies/bmgf_who_project/en/ index.html\#

12. Rabies: The official launch of a rabies elimination programme funded by the Gates Foundation and coordinated by WHO will take place in the Richards Bay/Uthungulu area of KwaZulu-Natal province in South Africa on 22 April 2011. World Health Organization [homepage on the Internet]. 2011. Available from: http://www.who.int/rabies/WHO_ coordinated_rabies_elimination_KwaZuluNatal/en/index.html

13. Sacks JJ, Kresnow M, Houston B. Dog bites: how big a problem? Inj Prev. 1996;2(1):52-54.

14. Eng TR, Fishbein DB, Talamante HE, et al. Urban epizootic of rabies in Mexico: epidemiology and impact of animal bite injuries. Bull World Health Organ. 1993;71(5):615-624.

15. Langley J. The incidence of dog bites in New Zealand. NZ Med J. 1992;105(927):33-35.

16. Cleaveland S, Fevre EM, Kaare M, Coleman PG. Estimating human rabies mortality in the United Republic of Tanzania from dog bite injuries. Bull World Health Organ. 2002,80(4):304-310.

17. Love M, Overall KL. How anticipating relationships between dogs and children can help prevent disasters. J Am Vet Med Assoc. 2001;219(4):446-453. 